\title{
Efficacy of different fixation techniques in repair of anterior mandibular fractures
}

\author{
Original \\ Abdel Aziz Baiomy Abdullah Baiomy', Altaib A. Mohammed $^{2}$ \\ Article \\ ${ }^{1}$ Assistant Professor of Oral and Maxillofacial Surgery, Faculty of Dental Medicine, \\ Al-Azhar University, Assiut, Egypt \\ ${ }^{2}$ Lecturer of Oral and Maxillofacial Surgery, Faculty of Oral and Dental Medicine, \\ South Valley University, Qena, Egypt t
}

\begin{abstract}
Objective: To compare between double straight miniplates, double inverted L- shaped miniplates , and three dimensional ( 3 D) rectangular miniplate in fixation of anterior mandibular (symphyseal / parasymphyseal area) fractures .

Patients and methods: Thirty adult patients with anterior mandibular fractures were included in this study. The patients were divided randomly into three equal groups, group I was treated by superior and inferior straight miniplate while group II was treated by double L- shaped miniplates fixation technique and group III was treated by 3D rectangular miniplate. Postoperative clinical, radiographic evaluation and quantitative measurements were performed.

Results: Wound healing was optimal in all cases except two cases in group I and one case in group II. Satisfactory occlusion was obtained in all cases except three cases in group I where it had mild to moderate occlusal derangement. Other parameters including maximal mouth opening, sensory nerve function, and patient's tolerance to the plate were comparable. There were the similarity between the density changes for the three groups as there was highly significant difference in G(I) compared to G(II) at six months, and G(I) compared to G(III) at three and six months also between G (II) compared to G(III) at six months. .

Conclusion: Both double L-shaped miniplates and 3D rectangular miniplate provided enough stability for proper bone healing, establishment of optimal occlusion and early return to normal function more than with double straight miniplates. Additionally, there is superiority of $3 \mathrm{D}$ rectangular miniplate over double inverted L- shaped miniplates in these parameters.
\end{abstract}

Key Words: Miniplates, parasymphyseal, stability, symphyseal.

Received:29 April 2018, Accepted:10 June 2018

Corresponding Author: Abdullah, Abdel Aziz, Associate Professor,Oral and Maxillofacial Surgery, Faculty of Dental Medicine, Al-Azhar University, Assiut, Egypt, E-mail: maizezo83@gmail.com

ISSN: 2090-097X, May 2018, Vol. 9, No. 2

\section{INTRODUCTION}

Mandibular fractures are the second most common facial fractures after the nasal bone. Symphyseal / parasymphyseal fracture comprises 15.6 to $29.3 \%$ of mandibular fractures ${ }^{[1]}$. Symphyseal fracture can be occurred when a trauma is directed towards the symphyseal region where compressive strain develops along the buccal aspect whereas tensile strain develops along the lingual aspect. This lead to a fracture that begins in the lingual plate and spreads toward the buccal plate ${ }^{[2]}$

Therefore, all internal fixation systems that can be used to manage of the symphyseal and parasymphyseal fractures must resists the different moments of force as bending and torsion when a midline fracture is present.
Where, activation of the masseteric sling will produce a rotation around an anteroposterior axis at the midline. The effect of this rotation and movement will be seen at the midline as separation of the lower border of the mandible greater than separation of the upper border ${ }^{[3,4]}$

For symphyseal and parasymphyseal fractures, numerous surgical techniques have been successfully applied, including closed reduction with MMF, lag screws, dynamic compression plates, and noncompression plates $^{[2,5,6]}$. However, there are ongoing controversies regarding the optimal internal fixation technique for symphyseal and parasymphyseal fractures. Where, rigid internal fixation require bicortical screw engagement to produce compression along the fracture line ${ }^{[7]}$. This 
necessitate their placement at inferior border to eliminate the damage to the inferior alveolar neurovascular structures or roots of the teeth ${ }^{[8]}$. In semi-rigid fixation, a doubt arises whether miniplate fixation is sufficiently stable for fractures that cannot be adequately reduced. On the other hand, biomechanical studies concluded that the use double L shaped plates for treatment of anterior mandibular fractures would be more stable with easy adaptation and fewer complications than other miniplates ${ }^{[9,10]}$.

To overcome shortcomings of rigid and semi-rigid fixation, 3-D bone plate was developed ${ }^{[11]}$. Where ,their geometry conceptually allows stability in three dimensions at both the superior and inferior borders of fracture, and resistance against forces while maintaining a low profile and malleability ${ }^{[12-15]}$.In the opposite side, some authors concluded that Champy's miniplate system is a better and easier method than the 3D miniplate system for fixation of mandibular fractures. Moreover, the 3D miniplate system is unfavorable for use in cases of oblique fractures and those involving the mental nerve, and is also difficult to $\operatorname{adapt}^{[16]}$.
Accordingly, because of a variety of different treatment modalities in anterior mandibular fracture (symphyseal or parasymphyseal fractures ) and still on going controversies about the preferred type of fixation, the present study aimed to evaluate the versatility of titanium $3 \mathrm{D}$ rectangular miniplate in repair of anterior mandibular fractures versus double straight , and L- shaped titanium miniplates fixation.

\section{PATIENTS AND MATERIALS}

Thirty adult patients (18 male and 12 female) with anterior mandibular fractures (symphyseal or parasymphyseal) were included in this study. Patients ranging in age from 24 to 49 years with sufficient dentition to reproduce the occlusion (table 1). All patients were selected from the Out-patient Clinic of Oral and Maxillofacial Surgery Department, Faculty of Dentistry, Al-Azhar university-Assiut branch over a period of 4 years (July 2013 -May 2017). They were informed of the need to attend 6 months of follow-up. The patients were required to provide informed consent or to refuse participation in the study.

Table (1): Demographic data of the patients.

\begin{tabular}{|c|c|c|c|c|c|c|}
\hline Groups & Case number & Age & Gender & Side of trauma & Cause of trauma & Associated fractures \\
\hline \multirow{10}{*}{ 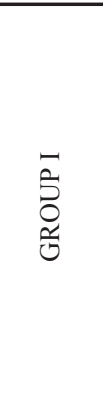 } & 1 & 24 & Male & Symphyseal & Fall from height & Bilateral subcondylar \\
\hline & 2 & 35 & Male & Symphyseal & RTA & Bilateral angel \\
\hline & 3 & 44 & Male & Right parasymphyseal & Fight & Left body \\
\hline & 4 & 29 & Female & Symphyseal & Fall from height & 0 \\
\hline & 5 & 38 & Female & Left parasymphyseal & RTA & Right body \\
\hline & 6 & 25 & Male & Symphyseal & RTA & Bilateral angel \\
\hline & 7 & 48 & Female & Symphyseal & RTA & Bilateral body \\
\hline & 8 & 49 & Male & Right parasymphyseal & Fight & Left body \\
\hline & 9 & 30 & Male & Bilateral parasymphyseal & Fall from height & 0 \\
\hline & 10 & 37 & Female & Symphyseal & RTA & Rt. Angel \\
\hline \multirow{10}{*}{ 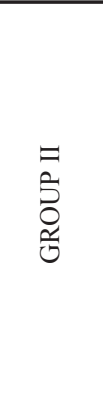 } & 1 & 45 & Female & Bilateral parasymphyseal & RTA & Bilateral subcondylar \\
\hline & 2 & 28 & Male & Symphyseal & RTA & Rt.\& left body \\
\hline & 3 & 25 & Male & Left parasymphyseal & Fall from height & Bilateral subcondylar \\
\hline & 4 & 40 & Female & Right parasymphyseal & RTA & Left angel \\
\hline & 5 & 29 & Male & Symphyseal & Fight & 0 \\
\hline & 6 & 27 & Male & Symphyseal & RTA & Left subcondylar \\
\hline & 7 & 24 & Female & Symphyseal & RTA & Bilateral subcondylar \\
\hline & 8 & 44 & Male & Bilateral parasymphyseal & RTA & Bilateral angel \\
\hline & 9 & 38 & Male & Symphyseal & RTA & 0 \\
\hline & 10 & 39 & Female & Left parasymphyseal & Fall from height & Right angel \\
\hline \multirow{10}{*}{\begin{tabular}{l} 
目 \\
S \\
0 \\
\multirow{0}{0}{}
\end{tabular}} & 1 & 28 & Male & Left parasymphyseal & Fight & 0 \\
\hline & 2 & 25 & Male & Right parasymphyseal & RTA & Left body \\
\hline & 3 & 31 & Female & Bilateral parasymphyseal & Fall from height & Bilateral subcondylar \\
\hline & 4 & 24 & Male & Left parasymphyseal & RTA & Left angel \\
\hline & 5 & 44 & Female & Symphyseal & RTA & Unilateral subcondylar \\
\hline & 6 & 41 & Male & Symphyseal & Fight & 0 \\
\hline & 7 & 39 & Female & Symphyseal & Fall from height & Bilateral subcondylar \\
\hline & 8 & 40 & Female & Bilateral parasymphyseal & RTA & 0 \\
\hline & 9 & 38 & Female & Right parasymphyseal & RTA & Left body \\
\hline & 10 & 34 & Male & Symphyseal & Fight & 0 \\
\hline
\end{tabular}

$*$ RTA $=$ road traffic accident 


\section{Grouping:}

Patients were randomly assigned into three equal groups according to the type of fracture fixation.

- Group I: included 10 patients in whom, fractures were fixed by double a $2.0 \mathrm{~mm}$ straight miniplate placed at the superior and inferior border of fracture through an intraoral approach.

- Group II: included 10 patients, in whom fractures were fixed by double inverted a $2.0 \mathrm{~mm}$ L-shaped miniplates with a conventional monocortical screw was placed at both sides of fracture through an intraoral approach.

- Group III: consisted of 10 patients, in whom fractures were fixed by A 8-holed rectangular titanium 3D miniplate through an intraoral approach.

\section{Exclusion criteria:}

Patients with comminuted anterior mandibular fractures, local bone pathology infected fractures, age $<16$ years, or systemic diseases that affect bone healing and full edentulous patients were excluded.

\section{Preoperative evaluation:}

Thorough history was taken regarding; medical problems, time, type and direction of traumatic force; and any treatment performed before arrival. All patients were examined clinically by inspection and palpation both extraorally and intraorally.

\section{Preoperative radiological examination:}

Standardized preoperative panoramic or CT radiographs were performed for each patient to assess the number and location of fracture lines, degree of displacement, and to localize the inferior dental canal or tooth in the fracture lines.

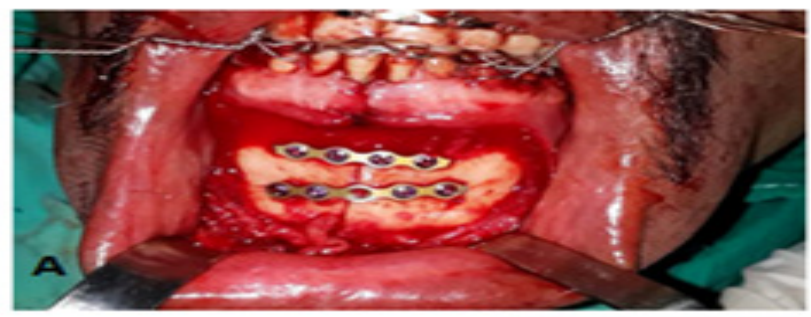
with a conventional monocortical screw was

\section{Surgical procedure:}

The operation was performed under general anaesthesia with nasotracheal intubation. The oral cavity was first scrubbed with povidone iodine, then all around extraoral surgical site followed by draping with sterile towels, exposing only the area of surgery.

- In group I, patients were treated with ORIF via an intraoral approach, in which two titanium 4-holed miniplates with gap having a thickness of $2.0 \mathrm{~mm}$ were used. The screws used were of 6.0 and $8.0 \mathrm{~mm}$ length. The plates were applied according to Champy's ideal line of osteosynthesis. A double 4-hole non-compression titanium miniplate (Stryker Leibinger Gmbh \& Co.kG, Germany ) were adapted at superior and inferior border of fracture after curving the plate, and were screwed to the bone using 2.0-mm self-threading screws ( fig. $1 \mathrm{a}$ ).

- In group II, patients were treated with ORIF via an intraoral approach, in which two L-shaped titanium 4-holed miniplates (Stryker Leibinger Gmbh \& Co.kG, Germany) with gap having a thickness of $2.0 \mathrm{~mm}$ were used. The screws used were of 6.0 and $8.0 \mathrm{~mm}$ length. The plates were applied at both sides of fracture in opposite direction (one in normal position and another in inverted position). After curving the plate, and were screwed to the bone using 2.0-mm self-threading screws (fig. $1 \mathrm{~b}$ ).

- In the group three, A 8-holed rectangular titanium 3D miniplate (Stryker Leibinger Gmbh \& Co.kG, Germany) was used in this study. A single plate was used in case of symphysis, parasymphysis; fixed with 6.0 and 8.0 $\mathrm{mm}$ screws. In the parasymphysis and body region, 3D miniplate was fixed above the level of mandibular canal. The lower border screws were fixed first followed by upper border screws. The 3D miniplate was placed in such a way so that horizontal cross bars are perpendicular to the fracture line and vertical cross bars are parallel to fracture line (fig. $1 \mathrm{c}$ ).
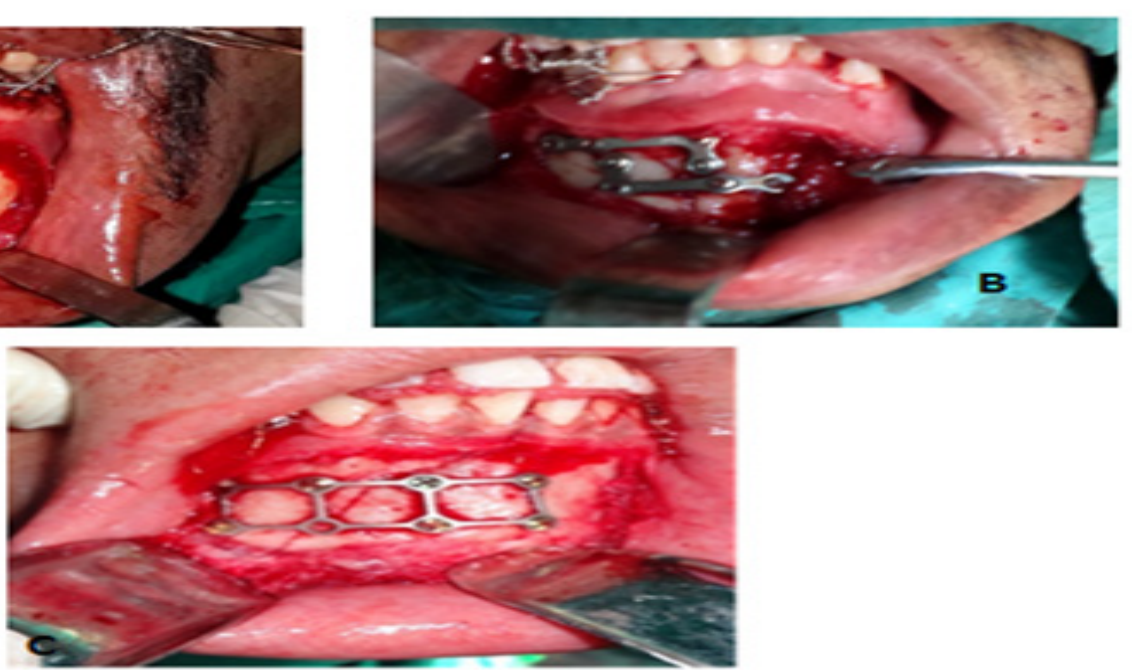

Fig. 1: Intraoperative photograph showing: A) anterior mandibular fracture fixed with double straight miniplates (group I) B) anterior mandibular fracture fixed with double inverted L-shaped miniplates (group II) C) anterior mandibular fracture fixed with 3D miniplate (group III). 


\section{Postoperative care:}

Postsurgical intermaxillary fixation (IMF) was used for 7 days in all patients. A pressure bandage was applied on the chin in all patients, as this was contributory in minimizing postoperative haematoma / oedema. All patients were given a 3-day course of systemic antibiotics and instructions on oral hygiene, including the use of chlorhexidine mouth rinse for 2 weeks. All patients were kept on a soft/ liquid diet.

\section{Postoperative evaluation:}

All patients were examined clinically and radiographically immediately, one month, three months and six months following operation.

\section{Clinical evaluation :}

Patients were evaluated for the following clinical parameters:

- Pain (on a visual analogue scale (VAS), with a value from 0 (no pain) to 10 (strongest pain or discomfort))

- Neurosensory dysfunction (none, hypoaesthesia, anaesthesia, dysaesthesia) and facial nerve paresis (yes/no);

- Inter-incisal dimension (mm) at last followup; occlusion (registered as satisfactory or unsatisfactory)

- Wound problems, including cellulitis, purulence, dehiscence of the incision, plate exposure, granulation tissue at incision, objectionable scarring (yes/no)

- Clinical union at last follow-up visit (yes/no) and stability of the fractured segments.

- Condition of teeth related to the fracture line

These observations were recorded by two oral and maxillofacial surgery residents who were not involved in the treatment planning or subsequent operative procedures; they were thus blinded to the treatment the patient had received (Histogram).

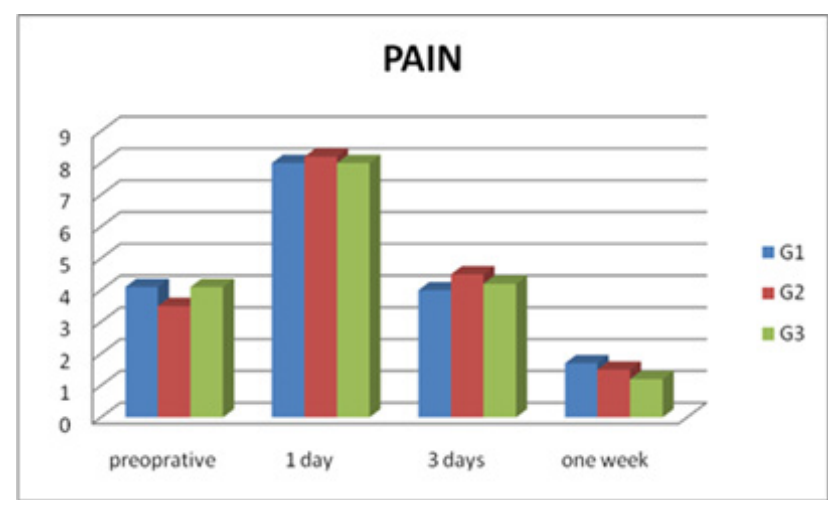

Histogram of pain showing the relationship between the groups at different time intervals

\section{Radiographic evaluation:}

Radiographic follow up was carried out through digital panoramic radiograph at the following intervals; immediate postoperative, one month, three month and six months postoperatively. Radiographic assessment was achieved through the following parameters:

1. Width of the fracture line.

2. Bone surrounding plate.

3. Teeth related to the fracture line.

All radiographs for every patient were imaged by the same electronically controlled panoramic machine (Orthophos 3, Sirona ,Dental systems GmbH fabrirkstr.31 D-64626 Bensheim, Germany ), the exposure parameters were considered fixed for all patients $70 \mathrm{kv}$ and $10 \mathrm{~A}$ for 15 seconds .Direct digital panoramic radiographs for all groups were carried out to assess the radiodensitometric bone changes in the fracture site immediate post operatively, one, three, six months post operatively .

\section{Radiographic analysis:}

\section{A) Qualitative analysis:}

Each panoramic image was evaluated for width of fracture line after reduction and alignment of the fractured segments.

B) Quantitative analysis (Radiodensitometric Analysis):

Digitized images were manipulated using the specially designed software of the Digora (Soredex). On each digital image, the mean gray value of the marked region of interest was calculated using the following steps:

1. Point A was selected at the fracture line and the pixel density of that point was measured on a scale from 0 to 255 according to its radiopacity, where the most radiopaque is 255 . Zero scale was given to the totally black regions (totally radiolucent), 255 for totally white regions while values in between represent different shades of grey.

2. A second point (point B) was selected at the same level and just beside the first area but at sound bone and the pixel density of it was also measured as before.

3. The difference between these two points was calculated representing the difference between bone density (pixel density) at the fracture line (point A) and at sound bone (point B). This show bone mineral density at region of interest.

In order to standardize the position of the point of interest under investigation, the exact coordinates ( $\mathrm{X}$ and $\mathrm{Y}$ coordinates) for each of point A and B calculated for each case and repeated during the follow up radiography

\section{Statistical analysis}

The data were collected and the significance of difference between groups was assessed by ANOVA followed by independent $t$ test. The collected data was 
coded and entered into statistical package of social sciences (SPSS-17, Chicago, Illinois, USA) program for statistical analysis.

\section{RESULTS}

\section{Postoperative clinical data}

- All patients were under went normal recovery period. All of the patients complained of severe pain during the first two days postoperatively. Mild postoperative edema was observed immediately after surgery and completely resolved by the end of the first week postoperatively.

- Pain (VAS) There was no statistically significant difference between the groups with regard to the pain VAS scores, except for the scores at the 1-week follow-up. VAS scores at 1-week follow-up were lower in group II (3.10 $+1.65) \&$ III $(2+1.3)$ than in group I $(4.10+1.93)$; the difference was statistically significant $(\mathrm{P}=0.0132)$.

- Soft tissue wounds showed primary healing after one week to ten days postoperatively. No signs of infection, or plate exposure were recorded or wound dehiscence (except two cases in group I and one case in group II complain with wound dehiscence) these conditions were controlled by proper oral hygiene and mouth washes .

\section{One month postoperative:}

- Wound dehiscence or plate exposures were not observed in any case.

- Measurements of mouth open were decrease compared to preparative measurements.
- Bimanual examination of the fractured segments revealed absolute stability and smooth uniform inferior border of the mandible could be palpated in all cases. Except 2 cases in group I, were mobility of the bony segments was detected, one case was due to presence of tooth in the fracture line who was treated by extraction of the tooth and IMF was done. While another case because of uncompleted bone formation at fracture line which was treated and supported by IMF.

- At the end of the follow up period, all cases were presented with normal occlusion, healthy soft tissue and proper alignment of mandibular inferior border. Except two cases in group I showed mild to moderate occlusal derangement which was treated after that. One of them had occlusal grinding done. The other patient had to be kept on IMF for another week with elastic bands.

\section{Three and six months postoperative:}

- All cases showed stability of the bony segments with no detected mobility of the bony segments.

- Measurement of mouth open increase compared to last months.

- No sensory or motor nerve dysfunction was reported or observed in any of the patients except case no. 4 in group II and case no. 3 in group III were still complaining of numbness of the lower lip and chin.

\section{Radiographic findings:}

Immediately and one month postoperatively
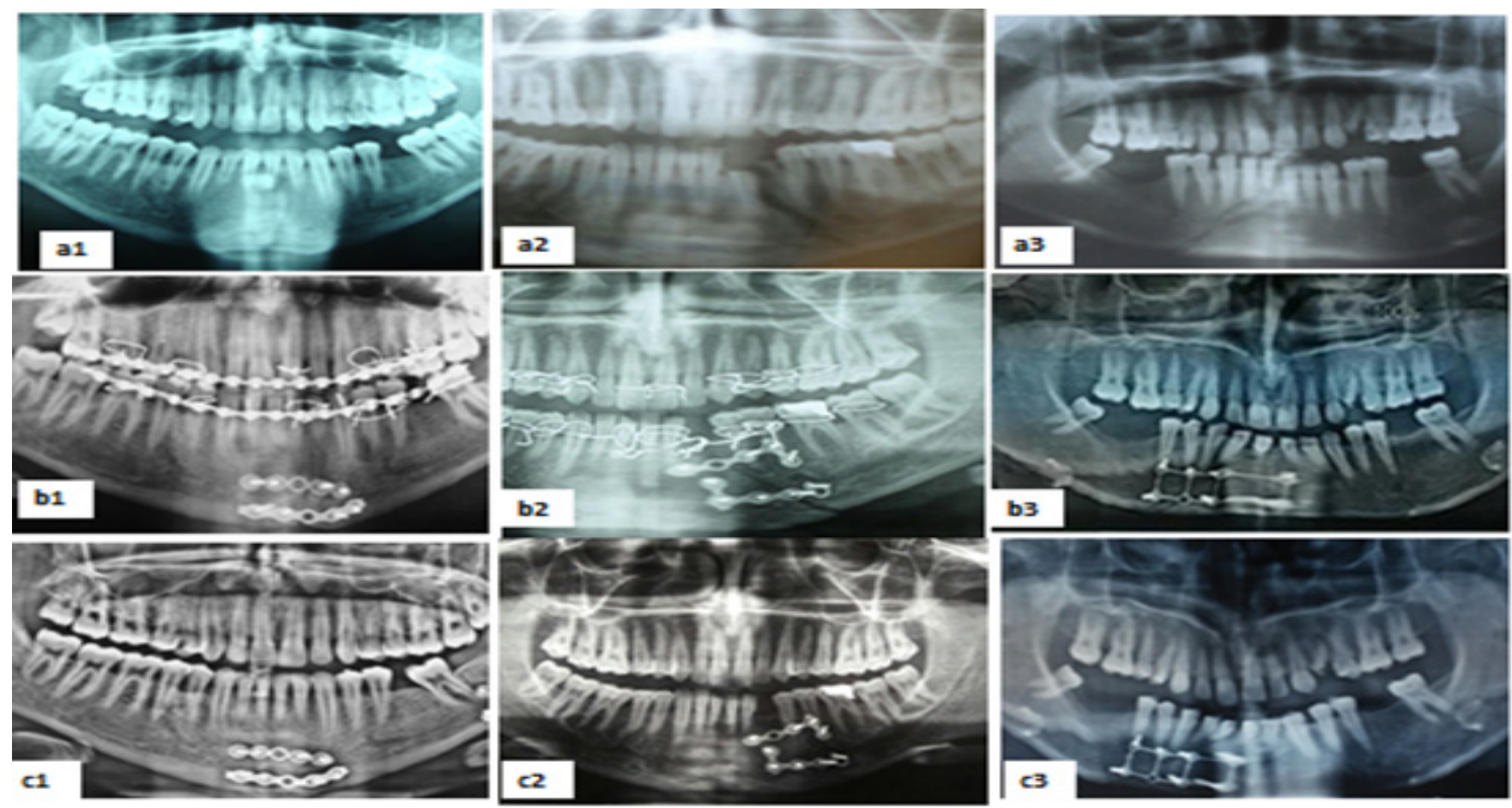

Fig. (2): Preoperative (a1\&2\&3) and postoperative orthopantomogram immediately (b1\&2\&3) and at 6 months (c1\&2\&3) for all groups. (1) Group I (2) Group II (3) Group III. 
radiographic examination of all cases revealed properly reduced fractured segments with narrowing of the interfragmentary gap without any significant difference appearing. In all cases the inferior border of the mandible was properly aligned.

At three months, radiographic examination revealed more healing of fracture lines with proper alignment of the inferior border of the mandible and the beginning of disappearance of interfragmentary gaps in group II and III (fig. 2 b \& c). On the opposite side, radiographic examination of group I showed interfragmentary gaps which could be defined by investigators (fig. a). At six months, Fracture line was become unidentifiable in all cases; no abnormal radiographic changes were seen in relation to both the plate and the teeth within the fracture line in all cases.

\section{Radiographic Analysis results for the fracture line:}

Table (2) demonstrate the mean and standard deviations of difference between bone density at the fracture line and at sound bone (bone mineral density at region of interest).Bone mineral densities (BMD) for three group were: In group (I) BMD was $56.07 \pm 12.7$ at postoperative immediately, $47 \pm 12.7$ at one month, $24.5 \pm 7.0$ at three months, and $12.1 \pm 2.8$ at six months. While in group II mean BMD was $59.7 \pm 8.02$ for immediate , $47.5 \pm 6.3$ for one month , $19.3 \pm 3.6$ for three months ,and $10.38 \pm$ 2.4 for six months. While in group III mean BMD was $59.5 \pm 6.7$ for immediate, $43.1 \pm 3.4$ for one month, 13.3 \pm 3.4 for three months , and $5.1 \pm 2.1$ for six months.

Table (2): Mean and standard deviation of bone density at different period of follow up for groups

\begin{tabular}{ccccc}
\hline G & IMMEDIATE & 1 MONTH & 3 MONTHS & 6 MONTH \\
\hline & Mean $\pm \mathrm{SD}$ & Mean $\pm \mathrm{SD}$ & Mean $\pm \mathrm{SD}$ & Mean $\pm \mathrm{SD}$ \\
$\mathrm{G} 1$ & $56.07 \pm 12.7$ & $47 \pm 12.7$ & $24.5 \pm 7.0$ & $12.1 \pm 2.8$ \\
$\mathrm{G} 2$ & $59.7 \pm 8.02$ & $47.5 \pm 6.3$ & $19.3 \pm 3.6$ & $10.38 \pm 2.4$ \\
& & & & \\
G3 & $59.5 \pm 6.7$ & $43.1 \pm 3.4$ & $13.3 \pm 3.4$ & $5.1 \pm 2.1$ \\
\hline
\end{tabular}

Table (3) reveals the similarity between the density changes for the three study groups as there was highly significant difference $(p<0.01)$ in $G(I)$ compared to $G($ II) at six months, and G(I) compared to G(III) at three and six months also between $\mathrm{G}(\mathrm{II})$ compared to $\mathrm{G}(\mathrm{III})$ at six months.
Table (3): Comparison of bone density between groups

\begin{tabular}{lcccccccccc}
\hline & & Immediate & & 1 month & & 3 months & & 6 month \\
\hline & T & P-value & $\mathrm{T}$ & P-value & $\mathrm{T}$ & P-value & $\mathrm{T}$ & P-value \\
& & & & & & & & \\
$\mathrm{G} 1$ & -3.6 & .718 & -.53 & .991 & -5.18 & $.040^{*}$ & -1.7 & $.004^{* *}$ \\
$\mathrm{G} 2$ & & & & & & & & \\
$\mathrm{G} 1$ & -3.4 & .744 & 3.8 & .643 & -10.9 & $.001 * *$ & -7.2 & $.000^{* *}$ \\
$\mathrm{G} 3$ & & & & & & & & \\
$\mathrm{G} 2$ & .20 & .999 & 4.3 & .584 & -5.81 & $.011^{*}$ & -5.4 & $.000^{* *}$ \\
$\mathrm{G} 3$ & & & & & & & & & \\
\hline
\end{tabular}

** High statistically significance when $\mathrm{p}<0.01$

* Statistically significance when $\mathrm{p}<0.05$

There was significant difference $(\mathrm{p}<0.05)$ in $\mathrm{G}(\mathrm{I})$ compared to $\mathrm{G}(\mathrm{II})$ at three months and between $\mathrm{G}(\mathrm{II})$ compared to $\mathrm{G}(\mathrm{III})$ at three months while there was no significant difference $(p>0.05)$ in $G(I)$ compared to $G(I I)$ at immediate and one month, in G(I) compared to G(III) at immediate and one month, and in G(II) compared to G(III) at immediate and one month.

\section{DISSUCTION}

The mandible is the second most commonly fractured bone of the maxillofacial skeleton. Aggregate analysis places anterior region at approximately 23\%of all mandibular fractures ${ }^{[1]}$. Anterior mandibular fractures (AMFs) are defined as mandibular fractures that involve a region bounded bilaterally by vertical lines just distal to the canine teeth (the parasymphesis) or linear fractures that run in the midline of mandible (symphesis). Patients with anterior mandibular fracture usually complain from pain that worsens with mastication and phonation movements, and even respiratory movements; sometimes there are facial asymmetry complaints. Therefore, treatment of mandibular fracture aims to re-establish normal occlusion and masticatory function with minimal disability and complications ${ }^{[17,18]}$.

Surgical treatment of mandibular fractures involves intraoral or extraoral pathway to the fracture site and direct osteosynthesis with transosseous wires, lag screws or bone plates $^{[19,20]}$ a complex form of biomechanical behavior at anterior mandibular fracture leaded to development several types for internal fixations to management of this type of fracture. However, there are ongoing controversies regarding the optimal internal fixation technique in anterior 
mandibular fracture. Accordingly, the present study was a trial to compare between double straight miniplates, double inverted L- shaped miniplates , and three dimensional (3D) rectangular miniplate in fixation of anterior mandibular (symphyseal / parasymphyseal area) fractures.

Results of the current study have showed greater stability and fewer complications in cases of group II \& III than cases of group I. Beside to , postoperative clinical observations of patients in group II \& III generally showed that perfect adjustment of occlusion and normal jaw movements were early achieved and this allows better care of oral hygiene and feeding. These results of our study were in accordance with Malhotra et al ${ }^{[21]}$.

In the current study, pain was evaluated using VAS scores on a scale of $0-10$. VAS scores at the 1 - week follow-up were lower in groups II \& III than in group I. This could be attributed to the large free areas between the plate arms of and minimal dissection in group II \&III permitting more blood supply to the bone than in group I leading to more washing action for inflammatory mediators from fracture region. This explanation matched with Malhotra et al. ${ }^{[21]}$, who evaluated Titanium $3 \mathrm{~d}$ plate in versus titanium miniplate fixation for the management of mandibular fracture.

No case of infection has occurred among patients treated with $3 \mathrm{D}$ rectangular miniplate. In the opposite side, one case in group II $(10 \%)$ and two cases in group I $\%)$. The reason for the absence of infection in group III could be attributed to good internal rigid fixation which provides proper rigidity and stability of fracture segment. These finding and explanations were in agreement with Rudderman et al ${ }^{(22)}$ who reported that the main reason for infection associated with rigid fixation is the failure to achieve stability even after placement of plates and screws. This is in the same side, with study of Guimand et al. ${ }^{[12]}$ which reported low incidence of wound dehiscence and plate exposure with 3-D miniplate in comparison to conventional miniplate that might be as a result of reduced operating time and periosteal stripping in 3-D miniplate fixation.

Results of the current study showed that all cases had normal occlusion, and healthy soft tissue. Except two cases in group I $(20 \%)$ showed mild to moderate occlusal derangement which was successfully treated by guiding elastics. This was attributable to instability because of strong muscular distractive forces overcome with weak osteosynthesis fixation device. This is in the same direction with results of with previous studies of Formand and Dupoirievx ${ }^{[23 \& 24]}$ which reported that 3 D miniplates have the Quadrangle shape as a geometrically stable configuration for support. Because of 3-D stability is achieved by the geometric shape that forms a cuboid, compared with standard miniplates and reconstruction plates. Although ,this is in opposite direction to Champy et al ${ }^{[25]}$ who advised the use of 2 miniplates in the anterior region, one at the inferior border and the second $5 \mathrm{~mm}$ above the lower plate.

Our results presented no sensory or motor nerve dysfunction was reported or observed in any of the patients except case no. 4 in group II and case no. 3 in group III who were still complaining of numbness of the lower lip and chin at end of study. These results can be explained by the differences in degree of displacement. When there is displacement of the fracture line, a greater incidence of sensory disorder and more prolonged recovery should be expected. This is same as Al-Tairi et al ${ }^{[26]}$ explanation for results of his study on mandibular angel fracture.

On radiographic assessment of the postoperative radiographs, adequate anatomic reduction was found in all groups with no distraction of the superior border and good lower border alignment. Radiographic examination revealed earlier healing of fracture lines with proper alignment of the inferior border of the mandible and the beginning of disappearance of interfragmentary gaps in group II and III than that in group I. This matched with radiographic analysis for bone density in all groups, which presented more bone density at fracture line in groups II \& III at earlier follow up period than group I with statistically significant difference between them. Statistical analysis for bone density values recorded the highest statistically significant difference for group III then for group II. This presented superiority of $3 \mathrm{D}$ rectangular miniplate over double inverted L-shaped miniplates and double straight miniplates. Although, double inverted L-shaped miniplates have higher statistically significant difference than double straight miniplates.

Our results were matched with the previous studies which reported that $3 \mathrm{D}$ miniplates can be considered a 2-plate system, with 2 miniplates

joined by interconnecting crossbars. Accordingly, double inverted L-shaped miniplates may be used as alternative to 3D miniplate ${ }^{[27-29]}$ Where, their shape is based on the principle of a quadrilateral as a geometrically stable configuration for support. This was explanted by Guimond et al ${ }^{[12]}$ which reported that because the screws arranged in the configuration of a box on both sides of the fracture, a broadband platform is created, increasing the resistance to twisting and bending of the long axis of the plate. There is a simultaneous stabilization of the tension and compression zones, making 3D plates a time-saving alternative to conventional miniplates.

In conclusion, the results of present study showed that double straight miniplates, double inverted L- shaped miniplates , and three dimensional (3D) rectangular miniplate are satisfactory methods of fixation in anterior mandibular (symphyseal / parasymphyseal area) fractures. But both double inverted L- shaped miniplates and three dimensional (3D) rectangular miniplate provided enough stability for proper bone healing, establishment of optimal occlusion, and early return to normal function more than with double straight miniplates. Beside to, superiority of 
three dimensional (3D) rectangular miniplate over double inverted L- shaped miniplates in these parameters.

\section{REFERENCES}

1. Rahpeyma A, Khajehahmadi S, Abdollahpour S. Mandibular Symphyseal Parasymphyseal Fracture with Incisor Tooth Loss: Preventing Lower Arch Constriction Craniomaxillofac Trauma Reconstr. 2016; 9 (1):15.

2. Larsen P. Traumatic injuries of the condyle. in Principles of oral and maxillofacial surgery, Larry j. Peterson volume 1, New York Lippincott 1999, page 935

3. Randal H. Rudderman, Robert L. Mullen John H. Phillips, M. The Biophysics of Mandibular Fractures: An Evolution toward Understanding. Plast. Reconstr. Surg.2008; 121: 596.

4. Tams J, van Loon J, Otten E, Rozema F, Bos R. A three-dimensional study of bending and torsion moments for different fracture sites in the mandible: an in vitro study. Int J Oral Maxillofac Surg 1997;26(5):383

5. Ellis E. A study of two bone plating methods for fractures of the mandibular symphysis/body. J Oral Maxillofac Surg 2011; 69:1978.

6. Ellis E. Is lag screw fixation superior to plate fixation to treat fractures of the mandibular symphysis? J Oral Maxillofa Surg 2012; 70:875.

7. Juergen Z. , Olivier L., and Tateyuki I. Use of straight and curved 3-Dimesional titanium miniplates for fracture fixation at the mandibular angle. J Oral Maxillofac. Surg. 2007; 65:1758.

8. Seth R., and Thaller W. Scott Mc Doald textbook of facial trauma. Miami, Florida ,USA Quintessence;2002 p:381.

9. Kameyama T, Sakamoto E, Takeshima H, Shimada J, Yamamoto Y.Mechanical study on the stability of multiform mini-plates. I. Double-Ttype plate (90, regular, 6-holes. Meikai Daigaku Shigaku Zasshi.1989;18(1):88.

10. Mohammed A. Effect of the shape of mini plate on the stability of mandibular fracture. International Journal of Dentistry Research 2017; 2(2): 49.

11. Al-Moraissi E, Mounair R, El-Sharkawy T, and El-Ghareeb T. Comparison between threedimensional and standard miniplates in the management of mandibular angle fractures: a prospective, randomized, double-blind, controlled clinical study. Int J Oral and Maxillofac. Surg. 2015(3):316.
12. Guimond C, Johnson JV, Marchena JM. Fixation of mandibular angle fractures with a $2.0-\mathrm{mm}$ 3-dimensional curved angle strut plate. J Oral Maxillofac Surg 2005;63(2):209.

13. Zix J, Lieger O, Iizuka T. Use of straight and curved 3-dimensional titanium miniplates for fracture fixation at the mandibular angle. J Oral Maxillofac Surg 2007; 65:1758.

14. Meyer C, Serhir L, Boutemi P. Experimental evaluation of three osteosynthesis devices used for stabilizing condylar fractures of the mandible. J Craniomaxillofac Surg 2006; 34:173.

15. Alkan A, Çelebi N, Özden B, Baş B , İnal S . Biomechanical comparison of different plating techniques in repair of mandibular angle fractures. Oral Surg Oral Med Oral Pathol Oral Radiol Endod. 2007; 104:752.

16. Jain M, Manjunath K, Bhagwan B, Shah D. Comparison of 3-Dimensional and Standard Miniplate Fixation in the Management of Mandibular Fractures. 2010; 68,(7), 1568.

17. Al-Moraissi E, Ellis E. Surgical Management of Anterior Mandibular Fractures: A Systematic Review and Meta-Analysis. Journal of Oral and Maxillofacial Surgery. 2014; 72(12):2507.

18. Omeje K, Adebola A, Efunkoya A, Osunde O, Bamgbose B, Akhiwu B. Prospective study of the quality of life after treatment of mandibular fractures. Br J of Oral and Maxillofac Surg. 2015; 53(4):342.

19. Cadhasivam G., Sanjay S., Ashisha S., and Ashisha Kumar S. An analysis of postoperative complication and efficacy of 3-D miniplates in fixation of mandibular fractures. Dental Res.J.2012; 9(2):414.

20. Ellis E, Throckmorton G. Open treatment of condylar process fractures: Assessment of adequacy of repositioning and maintenance of stability. J Oral -Maxillofac.Surg.2000; 58:27.

21. Malhotra K, Sharma A, Giraddi G and Kumar Shahi A. Versatility of Titanium 3D Plate in Comparison with Conventional Titanium Miniplate Fixation for the Management of Mandibular Fracture. J. Maxillofac. Oral Surg. 2012; 11(3):284.

22. Rudderman R, Mullen R. Biomechanics of the facial skeleton. Clin Plast Surg 1992; 19:11.

23. Formand M. and Dipoirievx L.: The value of 3-dimensional plate in maxillofacial surgery. $\mathrm{J}$ Oral Maxillfac Surg, 1992; 93:353.

24. Formand M.: The 3-D plating system maxillofacial surgery. J Oral Maxillfac Surg, 1993; 51:166. 
25. Champy M, Loddé JP, Schmitt R, Jaeger JH, Muster D. Mandibular osteosynthesis by miniature screwed plates via a buccal approach. J Maxillofac Surg 1978; 6:14.

26. Al-Tairi N, Shoushan M, Saad Khedr M, Abd-alal $\mathrm{S}$. Comparison of three-dimensional plate versus double miniplate osteosynthesis for treatment of unfavorable mandibular angle fractures. Tanta Dental Journal 2015; 12: 89.

27. Kalfarentzos EF, Deligianni D, Mitros G, Tyllianakis M: Biomechanical evaluation of plating techniques for fixing mandibular angle fractures: The introduction of a new 3D plate approach Oral Maxillofac Surg, 2009; 13:139.
28. Vineeth $\mathrm{K}$, Lalitha RM, Prasad $\mathrm{K}$, et al A comparative evaluation between single noncompression titanium miniplate and three dimensional titanium miniplate in treatment of mandibular angle fracture-A randomized prospective study. J Craniomaxillofac Surg 2013; 41:103.

29. Mohamed A. Effect of the shape of mini plate on the stability of mandibular fracture. International Journal of Dentistry Research 2017; 2(2): 49. 